Article

\title{
Impact of Thermal Radiation and Heat Source/Sink on MHD Time-Dependent Thin-Film Flow of Oldroyed-B, Maxwell, and Jeffry Fluids over a Stretching Surface
}

\author{
Abdul Samad Khan ${ }^{1, *}$, Yufeng Nie ${ }^{1}$ and Zahir Shah ${ }^{2}$ (D) \\ 1 Department of Applied Mathematics, School of Science, Northwestern Polytechnical University, Dongxiang \\ Road, Chang'an District, Xi'an 710129, China; yfnie@nwpu.edu.cn \\ 2 Department of Mathematics, Abdul Wali Khan University, Mardan 32300, KP, Pakistan; \\ zahir1987@yahoo.com \\ * Correspondence: abdulsamadkhan17@mail.nwpu.edu.cn
}

Received: 1 March 2019; Accepted: 27 March 2019; Published: 2 April 2019

\begin{abstract}
In this study paper, we examined the magnetohydrodynamic (MHD) flow of three combined fluids, Maxwell, Jeffry, and Oldroyed- B fluids, with variable heat transmission under the influence of thermal radiation embedded in a permeable medium over a time-dependent stretching sheet. The fluid flow of liquid films was assumed in two dimensions. The fundamental leading equations were changed to a set of differential nonlinear and coupled equations. For this conversion, suitable similarity variables were used. An optimal tactic was used to acquire the solution of the modeled problems. The convergence of the technique has been shown numerically. The obtained analytical and numerical consequences are associated graphically and tabulated. An excellent agreement was obtained between the homotropy analysis method (HAM) and numerical methods. The variation of the skin friction and Nusslet number and their influence on the temperature and concentration profiles were scrutinized. The influence of the thermal radiation, unsteadiness effect, and MHD were the main focus of this study. Furthermore, for conception to be physically demonstrated, the entrenched parameters are discussed graphically in detail along with their effect on liquid film flow.
\end{abstract}

Keywords: Jeffrey, Maxwell, Oldroyed-B fluids; unsteady stretching surface; magnetic field; homotropy analysis method (HAM)

\section{Introduction}

In the last few years, thin film flow problems have received great attention because of the importance of thin film flows in various technologies. The investigation of thin film flow has obtained importance by its vast application and uses in engineering, technology, and industries. Cable, fiber undercoat, striating of foodstuff, extrusion of metal and polymer, constant forming, fluidization of the device, elastic sheets drawing, chemical treating tools, and exchanges are several uses. In surveillance of these applications, researchers have paid attention to cultivating the examination of liquid film on stretching surface. Emslie et al. [1] investigated thin film flow with applications. During the disk rotating process, they considered the balance between centrifugal and viscous forces. They simplified the Navier-Stokes equations and concluded that the film is uniformly maintained with its continuous thinning property. Higgins [2] considered the influence of the film inertia over a rotating disk. A liquid film over a rotating plate with constant angular velocity was analyzed by Dorfman [3]. The fluid film rotation on an accelerating disk was analyzed by Wang et al. [4]. For the thin and thick film parameter and small accelerating parameters, the asymptotic solutions were obtained. Andersson et al. [5] 
asymptotically and numerically examined the magnetohydrodynamics (MHD) liquid thin film due on a rotating disk. Over a rotating disk, Dandapat and Singh [6] examined the two layer film flow. The heat transfer flow of thin film flow of nonfluids was deliberated on by Sandeep et al. [7]. Recently, researchers [8-15] examined non-Newtonian nanofluid thin films using different models in different geometries and obtained useful results.

Jeffrey, Maxwell, and Oldroyed-B nanofluids have certain importance in the area of fluid mechanics because of the stress relaxation possessions. Kartini et al. [16] studied the two-dimensional MHD flow and heat transfer of Jeffrey nanofluid over an exponentially stretched plate. Hayat et al., [17] studied the convection of heat transfer in two-dimensional flow of Oldroyed-B nanofluid over a stretching sheet under radiation, and they also found that, with the escalation in radiation parameter, the temperature profile of the nanofluid escalates. Raju et al. [18] debated the presence of a homogenous-heterogeneous reaction in the nonlinear thermal radiation effect on Jeffrey nanofluid flow. Hayat et al. [19] presented a series solution of MHD flow of Maxwell nanofluid over a permeable stretching sheet with suction and injection impacts. Sandeep et al. [20] studied the unsteady mixed convection flow of micropolar fluid over a stretching surface with a non-uniform heat source. Nadeem et al. [21] discussed the heat and mass transfer in peristaltic motion of Jeffrey nanofluid in an annulus. Sheikholeslami [22,23] discussed the hydrothermal behavior of nanofluids flow due to external heated plates. Shah et al. [24-29] investigated MHD nanofluid flow heat transfer, and they mathematically analyzed it with Darcy-Forchheimer phenomena and Cattaneo-Christov flux impacts. Nanofluid flow was studied between parallel plates and stretching sheets. They used analytical and numerical approaches and obtained excellent results. Dawar et al. [30] analyzed the MHD carbon nanotubes (CNTs) Casson nanofluid in rotating channels. Khan et al. [31] studied the 3-D Williamson nanofluid flow over a linear stretching surface.

Lee [32] was the first to investigate the flow with a high Reynolds number (boundary layer concept) over a thin body with variable thickness. In engineering science, the variable thickness extending sheet has many more applications compared to the flat sheet. For instance, for a straightly-extending sheet of an incompressible material, if the extending speed is directly relative to the separation from the slot, the sheet thickness diminishes straightly with the separation. For different materials with various extensibility, the plate/sheet thickness may change as indicated by different profiles. An extending plate/sheet with variable thickness is more realistic. Peristaltic flow of two layers of power law fluids was studied in Usha et al. [33]. Eegunjobi and Makinde [34] mutually derived the effect of buoyancy force and Navier slip in a channel of vertical pores on entropy generation. Numerical analyses of the buoyancy force's influence on the unsteady flow of hydromagnetic by a porous channel with injection/suction were presented by Makinde et al. [35].

Many mathematical problems in the field of engineering and science are complicated, and it is often impossible to solve these types of problems exactly. To find an approximate solution, numerical and analytical techniques are widely implemented in the literature. Liao in 1992 [36,37] investigated the solution of such types of problems by implementing a new proposed technique. This technique was named the homotropy analysis method. He further discussed the convergence of the newly implemented method. A solution is a function of a single variable in the form of a series. Due to fast convergence and strong results, many researchers [38-45] used the homotropy analysis method. Another powerful analytical tool to solve differential equations is the Lie algebra method [46-48].

The goal of the present study was to inspect the MHD flow of three combined nanofluids (Maxwell, Oldroyed-B, and Jeffrey) over a linear stretching surface. The fundamental leading equations were changed to a set of differential nonlinear equations with the support of appropriate correspondence variables. An optimal tactic was used to achieve the solution of the modeled equations, which is nonlinear. The effects of all embedding parameters were studied graphically. Boundary layer methodology was used in the mathematical expansion. The influences of the skin friction, Nusselt number, and Sherwood number on the velocity profile, temperature profile, and concentration profile, respectively, were studied. 


\section{Problem Formulation}

Consider a time-dependent and electric-conducting thin film flow of magnetohydrodynamic Jeffrey, Maxwell, and Oldroyed-B thin film liquids while extending a plate. The flexible sheet starts from an inhibiting slit, which is immovable at the descent of the accommodating system. The Cartesian accommodating system oxyz is adjusted in a well-known manner where ox is equivalent to the plate and oy is smooth to the sheet. The surface of the flow is stretched, applying two equivalent and reversed forces along the $\mathrm{x}$-axis and keeping the origin stationary. The $\mathrm{x}$-axis is taking along the extending surface with stressed velocity $U_{w}(x, t)=\frac{b x}{1-\alpha t}$, in which $\alpha, b$ are constant and the $y$-axis is perpendicular to it. $T_{w}(x, t)=T_{0}+T_{r}\left(\frac{b x^{2}}{2 v_{f}}\right)(1-\alpha t)^{-1.5}$ is the wall temperature of the fluid, $v_{f}$ represents the kinematic viscidness of the fluid, and $T_{0}, T_{r}$ are slits. An exterior magnetic ground $B(t)=B_{0}(1-\alpha t)^{-0.5}$ is given normally to the extending sheet (as shown in Figure 1). All the body forces are ignored in the flow field.

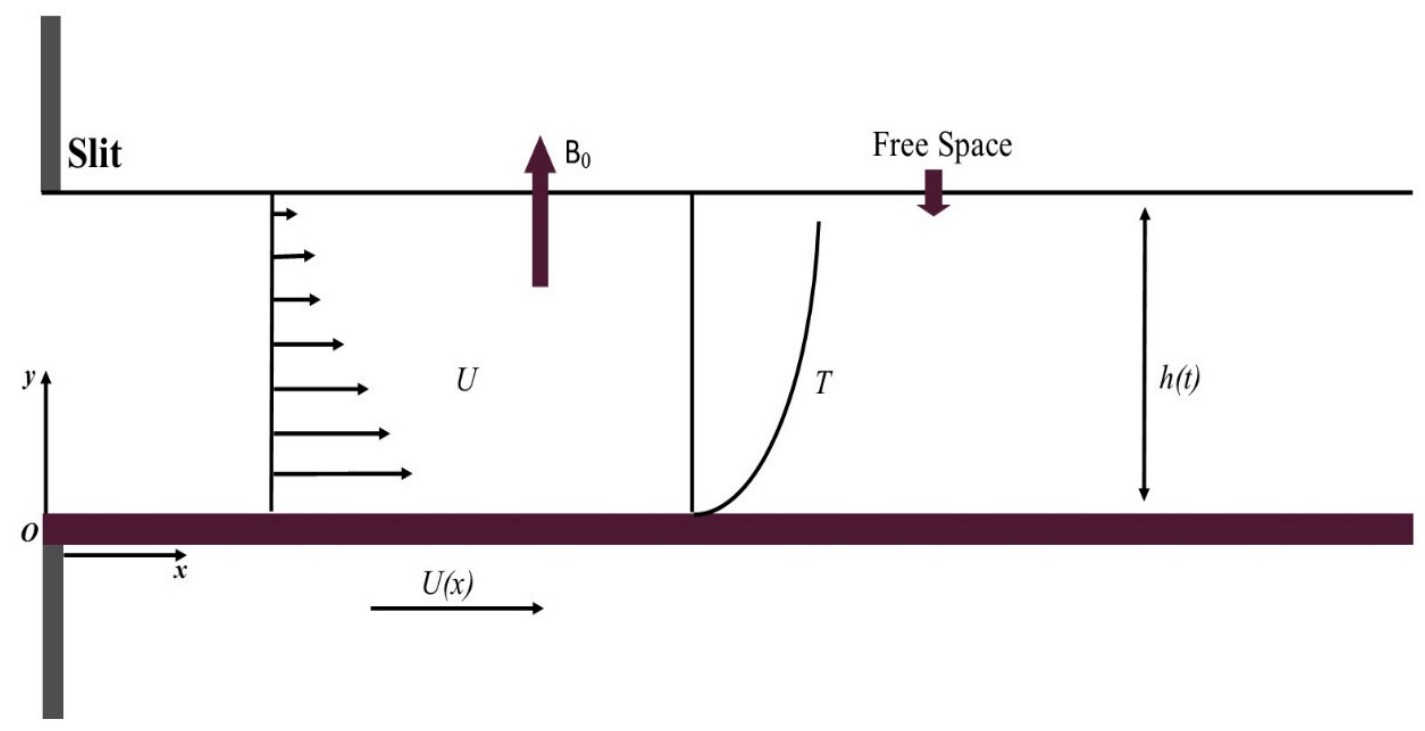

Figure 1. Geometry of the problem.

Considering these hypotheses, the continuity equation, the elementary boundary governing equation, and the heat transfer and concentration equations can be stated as:

$$
\begin{gathered}
u_{x}+u_{y}=0 \\
\rho_{f}\left[u_{t}+u u_{x}+v u_{y}+\lambda_{1}\left(u^{2} u_{x x}+v^{2} u_{y y}+2 u v u_{x y}\right)\right]= \\
\frac{\mu_{f}(T)}{1+\lambda_{2}}\left[u_{y y}+\lambda_{3}\left(u_{t y y}+u u_{x y y}+v u_{y y y}-u_{x} u_{y y}+u_{y} u_{x y}\right)\right]-\sigma_{n f} B^{2}(t) u, \\
T_{t}+u T_{x}+v T_{y}=\frac{1}{\rho c_{p}} T_{y y}+\frac{Q}{\rho c_{p}} T_{s}-T_{0}-\frac{1}{\rho c_{p}} q_{y}
\end{gathered}
$$

The applicable boundary conditions are:

$$
\begin{gathered}
u=U_{w}, v=0, T=T_{w} \text { at } y=0, \\
u_{x}=0, T_{x}=0, \text { at } y=h
\end{gathered}
$$

where $\vartheta_{r d}$ is:

$$
\vartheta_{r d}=-\frac{16 \varphi}{3 \hat{k}} T_{y}^{4}
$$


Applying Taylor series expansion on $T^{4}$, we get:

$$
T^{4}=T_{0}^{4}+4 T_{0}^{3}\left(T-T_{0}\right)^{2}+\ldots
$$

By ignoring higher-order terms:

$$
T^{4}=4 T T_{0}^{3}-3 T_{0}^{4}
$$

on which $u, v$ are the velocity constituents alongside the $\mathrm{x}$ and y-axes, respectively, $\sigma$ is the electric conductive parameter, $\mu, \rho_{f}, v_{f}$ are the dynamic viscosity, density, and kinematic viscosity, respectively and $\gamma_{1}, \gamma_{2}, \gamma_{3}$ represents the relaxation and retardation time ratios. $B(t)$ characterizes the applied magnetics pitch, $T_{s}$ represents the temperature of the fluid, and $T_{w}$ characterizes the temperature. Equation (2) manages distinctive fluid models dependent on the below conditions [7]:

I. The fluid should be Jeffrey fluid when $\lambda_{1}=0, \lambda_{2} \neq 0, \lambda_{3} \neq 0$;

II. The fluid should be Maxwell fluid when $\lambda_{1} \neq 0, \lambda_{2}=0, \lambda_{3}=0$;

III. The fluid should be Oldroyed-B fluid when $\lambda_{1} \neq 0, \lambda_{3} \neq 0 \lambda_{2}=0$.

Considering the above similarity transformations:

$$
\begin{aligned}
& \psi=x \sqrt{\frac{v b}{1-a t}} f(\eta), u=\psi_{y}=\frac{b x}{(1-a t)} f^{\prime}(\eta), \\
& v=-\psi_{x}=-\sqrt{\frac{v b}{1-a t}} f(\eta), \eta=\sqrt{\frac{b}{v(1-a t)}} y, y=\sqrt{\frac{v(1-a t)}{b}} \\
& \phi(\eta)=\frac{T-T_{0}}{T_{w}-T_{0}}
\end{aligned}
$$

where prime specifies the derivative with respect to $\eta$ and $\psi$ indicates the stream function, $h(t)$ specifies the liquid film thickness, and $v=\frac{\mu}{\rho}$ is the kinematics viscosity. The dimensionless film thickness $\beta=$ $\sqrt{\frac{b}{v(1-\alpha t)}} h(t)$, which gives $h_{t}=-\frac{\alpha \beta}{2} \sqrt{\frac{v}{b(1-\alpha t)}}$. Substituting Equation (9) into Equations (1)-(6) gives L

$$
\begin{gathered}
\frac{1}{\left(1+\lambda_{2}\right)}\left[f^{\prime \prime \prime}+\lambda_{3}\left\{\left(f^{\prime \prime}\right)^{2}-f f^{i v}+S\left(2 f^{\prime \prime \prime}+\frac{\eta}{2} f^{i v}\right)-M f^{\prime}\right\}\right]+ \\
(1+\varepsilon \kappa)\left[f f^{\prime \prime}-\left(f^{\prime}\right)^{2}-S\left(2 f^{\prime}+\frac{\eta}{2} f^{\prime \prime}\right)-\lambda_{1}\left((f)^{2} f^{\prime \prime \prime}-2 f f^{\prime} f^{\prime \prime}\right)\right]=0 \\
(1+R d) \theta^{\prime \prime}-\operatorname{Pr}\left\{\frac{S}{2}\left(3 \theta^{\prime}+\eta \theta^{\prime}\right)+\left(2 f^{\prime}-q\right) \theta-\theta^{\prime} f\right\}=0
\end{gathered}
$$

The boundary constraints are:

$$
\begin{gathered}
f(0)=0, f^{\prime}(0)=1, \theta(0)=1, \\
f(\beta)=\frac{S \beta}{2}, f^{\prime \prime}(\beta)=0, \theta^{\prime}(\beta)=0
\end{gathered}
$$

Skin friction is defined as $C_{f}=\frac{\left(\widetilde{S}_{x y}\right)_{y=0}}{\rho \widetilde{u}_{w}^{2}}$,

$$
C_{f}=\frac{1+\lambda_{1}}{1+\lambda_{2}} f^{\prime \prime}(0)
$$

The Nusselt number is:

$$
\begin{gathered}
u=\frac{Q_{w}}{\hat{k}\left(T-T_{h}\right)}, \\
u=\frac{1}{2}(1-\alpha t)^{-\frac{1}{2}}-\theta^{\prime}(0) R e^{-\frac{1}{2}} f_{x}
\end{gathered}
$$


After generalization, the physical constraints are as follows: $\lambda_{1}, \lambda_{2}, \lambda_{3}$ are the parameters of relaxation and retardation ratios, $S=\frac{a}{b}$ is the measure of unsteadiness of the nondimensional, $M=\frac{\sigma_{f} B_{0}^{2}}{b \rho_{f}}$ denotes the magnetic field parameter, and $P r=\frac{\rho v c_{p}}{k}$ denotes the Prandtl number.

\section{Solution by HAM}

Equations (8)-(10), considering the boundary condition in Equation (11), are solved with HAM. The solutions encircled the auxiliary parameter $h$, which normalizes and switches to a conjunction of the solutions.

The following is the initial guess:

$$
f_{0}(\eta)=\frac{(2-S) \eta^{3}+(3 S-6) \beta \eta^{2}+4 \beta^{2} \eta}{4 \beta^{2}}, \theta(\eta)=1
$$

$L_{f}, L_{\theta}$ reperesent linar operators:

$$
L_{f}(f)=f^{i v}, L_{\theta}(\theta)=\theta^{\prime}
$$

where:

$$
L_{f}\left(\frac{e_{1}}{6} \eta^{3}+\frac{e_{2}}{2} \eta^{2}+e_{3} \eta+e_{4}\right)=0, L_{\theta}\left(e_{5}+e_{6} \eta\right)=0
$$

Non-linear operators $N_{f}, N_{\theta}$ are given as:

$$
\begin{aligned}
& N_{f}[f(\eta ; r)]=\frac{1}{\left(1+\lambda_{2}\right)}\left[\begin{array}{c}
\frac{\partial^{3} f(\eta ; r)}{\partial \eta^{3}}+\lambda_{3}\left(\frac{\partial^{2} f(\eta ; r)}{\partial \eta^{2}}\right)^{2}-f(\eta ; r) \frac{\partial^{4} f(\eta ; r)}{\partial \eta^{4}}+ \\
S\left(2 \frac{\partial^{3} f(\eta ; r)}{\partial \eta^{3}}+\frac{\eta}{2} \frac{\partial^{4} f(\eta ; r)}{\partial \eta^{4}}\right)-M \frac{\partial f(\eta ; r)}{\partial \eta}
\end{array}\right]+ \\
&(1+\varepsilon \kappa)\left[\begin{array}{c}
f(\eta ; r) \frac{\partial^{2} f(\eta ; r)}{\partial \eta^{2}}-\left(\frac{\partial f(\eta ; r)}{\partial \eta}\right)^{2}-S\left(2 \frac{\partial f(\eta ; r)}{\partial \eta}+\frac{\eta}{2} \frac{\partial^{2} f(\eta ; r)}{\partial \eta^{2}}\right)- \\
\lambda_{1}\left((f(\eta ; r))^{2} \frac{\partial^{3} f(\eta ; r)}{\partial \eta^{3}}-2 f(\eta ; r) \frac{\partial f(\eta ; r)}{\partial \eta} \frac{\partial^{2} f(\eta ; r)}{\partial \eta^{2}}\right)
\end{array}\right] \\
& N_{\vartheta}[f(\eta ; r), \theta(\eta ; r)] \\
&=(1+R d) \frac{\partial^{2} \theta(\eta ; r)}{\partial \eta^{2}} \\
&-\operatorname{Pr}\left\{\begin{array}{c}
\frac{S}{2}\left(3 \theta(\eta ; r)+\eta \frac{\partial \theta(\eta ; r)}{\partial \eta}\right)+ \\
\left(2 \frac{\partial f(\eta ; r)}{\partial \eta}-q\right) \theta(\eta ; r)-f(\eta ; r) \frac{\partial \theta(\eta ; r)}{\partial \eta}
\end{array}\right\}
\end{aligned}
$$

The 0th-order problem is defined as:

$$
\begin{gathered}
L_{f}\left[f(\eta ; r)-f_{0}(\eta)\right](1-r)=r_{f} N_{f}[f(\eta ; r)] \\
L_{\theta}\left[\theta(\eta ; r)-\theta_{0}(\eta)\right](1-r)=r_{\theta} N_{\theta}[f(\eta ; r), \theta(\eta ; r)]
\end{gathered}
$$

The correspondent boundary constraints are:

$$
\begin{aligned}
& \left.f(\eta ; r)\right|_{\eta=0}=0,\left.\frac{\partial f(\eta ; r)}{\partial \zeta}\right|_{\eta=0}=1,\left.\frac{\partial^{2} f(\zeta ; r)}{\partial \eta^{2}}\right|_{\eta=\beta}=0,\left.f(\eta ; r)\right|_{\eta=\beta}=0 \\
& \left.\vartheta(\eta ; r)\right|_{\eta=0}=1,\left.\frac{\partial \theta(\eta ; r)}{\partial \eta}\right|_{\eta=\beta}=0,
\end{aligned}
$$

In the case of $r=0, r=1$ :

$$
f(\eta ; 1)=f(\eta), \theta(\eta ; 1)=\theta(\eta)
$$


After applying Taylor's series:

$$
\begin{gathered}
f(\eta ; r)=f_{0}(\eta)+\sum_{n=1}^{\infty} f_{n}(\eta) r^{n} \\
\theta(\eta ; r)=\theta_{0}(\eta)+\sum_{n=1}^{\infty} \theta_{n}(\eta) r^{n}
\end{gathered}
$$

where:

$$
f_{n}(\eta)=\left.\frac{1}{n !} \frac{\partial f(\eta ; r)}{\partial \eta}\right|_{r=0}, \theta_{n}(\eta)=\left.\frac{1}{n !} \frac{\partial \theta(\eta ; r)}{\partial \eta}\right|_{r=0}
$$

The subordinate limitations $\hbar_{f}, \hbar_{\theta}$ are selected such that the series in Equation (23) converges at $r=1$. Switching $r=1$ in Equation (23), we obtain:

$$
\begin{gathered}
f(\eta)=f_{0}(\eta)+\sum_{n=1}^{\infty} f_{n}(\eta), \\
\theta(\eta)=\theta_{0}(\eta)+\sum_{n=1}^{\infty} \theta_{n}(\eta),
\end{gathered}
$$

The $n$ th-order problem:

$$
\begin{gathered}
L_{f}\left[f_{n}(\eta)-\chi_{n} f_{n-1}(\eta)\right]=\hbar_{f} R_{n}^{f}(\eta), \\
L_{\theta}\left[\theta_{n}(\eta)-\chi_{n} \theta_{n-1}(\eta)\right]=\hbar_{\theta} R_{n}^{\theta}(\eta),
\end{gathered}
$$

The consistent boundary conditions are:

$$
\begin{aligned}
& f_{n}(0)=f_{n}^{\prime}(0)=\theta_{n}(0)=0 \\
& f_{n}(\beta)=f_{n}^{\prime \prime}(\beta)=\theta_{n}^{\prime}(\beta)=0
\end{aligned}
$$

and:

$$
\chi_{n}=\left\{\begin{array}{l}
0, \text { if } r \leq 1 \\
1, \text { if } r>1
\end{array}\right.
$$

\section{HAM Solution Convergence}

In this section, the convergence of the problem of the modeled and solved equations is discussed. Figure 2 presents the $h$-curves of the combined temperature and velocity functions. A valid region of convergent is observed in Figure 2. In Table 1, numerical convergence is presented. A fast convergence of HAM is shown in Table 1.

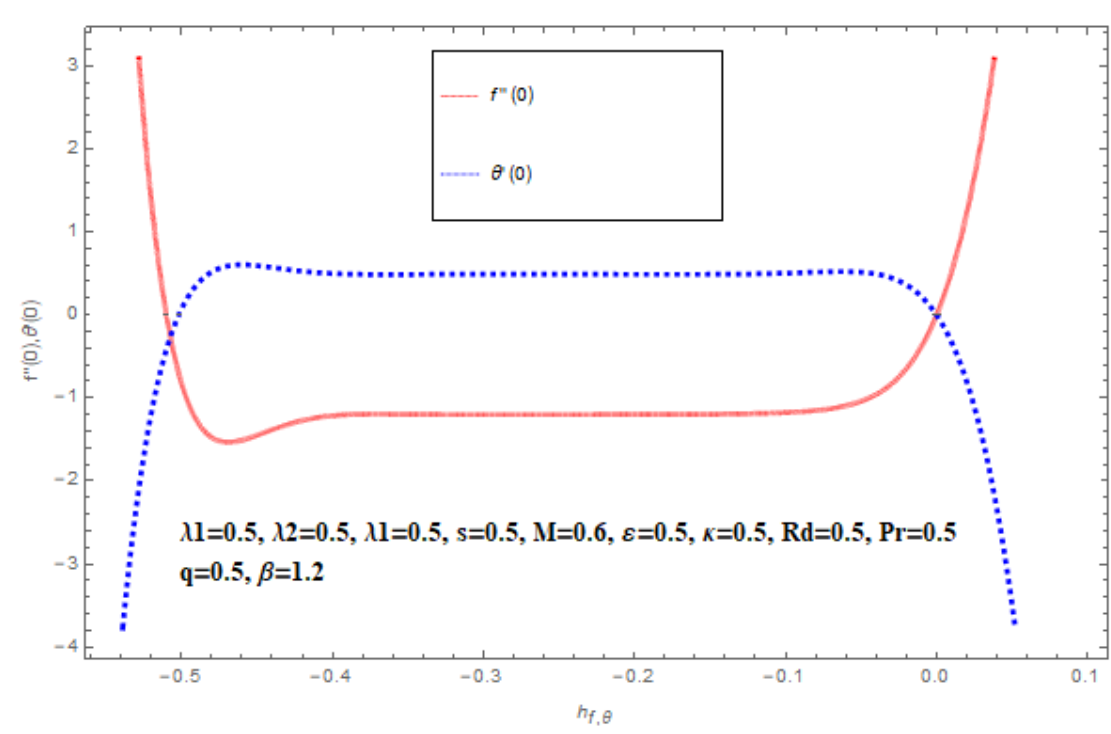

Figure 2. The combined h-curve graph of the velocity and temperature profiles. 
Table 1. Fast convergence of HAM (homotropy analysis method).

\begin{tabular}{ccc}
\hline Solution Approximations & $f^{\prime}(0)$ & $\boldsymbol{\theta}^{\prime}(0)$ \\
\hline $\mathbf{1}$ & 0.448400 & 0.122519 \\
\hline $\mathbf{4}$ & 0.858574 & -0.282846 \\
\hline $\mathbf{7}$ & 0.912994 & -0.356251 \\
\hline $\mathbf{1 0}$ & 0.920043 & -0.369590 \\
\hline $\mathbf{1 3}$ & 0.920946 & -0.372026 \\
\hline $\mathbf{1 6}$ & 0.921062 & -0.372472 \\
\hline $\mathbf{1 9}$ & 0.921077 & -0.372554 \\
\hline $\mathbf{2 5}$ & 0.921080 & -0.372569 \\
\hline $\mathbf{2 8}$ & 0.921080 & -0.372572 \\
\hline
\end{tabular}

\section{Results and Discussion}

This work investigated thin particle flow (Maxwell, Jeffry, and Oldroyed-B) fluids considering the influence of MHD and radiation with a time-dependent porous extending surface. This subsection presents the physical impact of dissimilar implanting parameters over velocity distributions $f(\eta)$ and temperature distribution $\Theta(\eta)$ as exemplified in Figures 2-12.

Figure 3 shows the effect of $\kappa$ on velocity field $f(\eta)$. There is a direct relation between the cohesive and adhesive forces and viscosity. The overall fluid motion is reduced due to the rising in $\kappa$, which generates strong cohesive and adhesive forces that cause resistance.

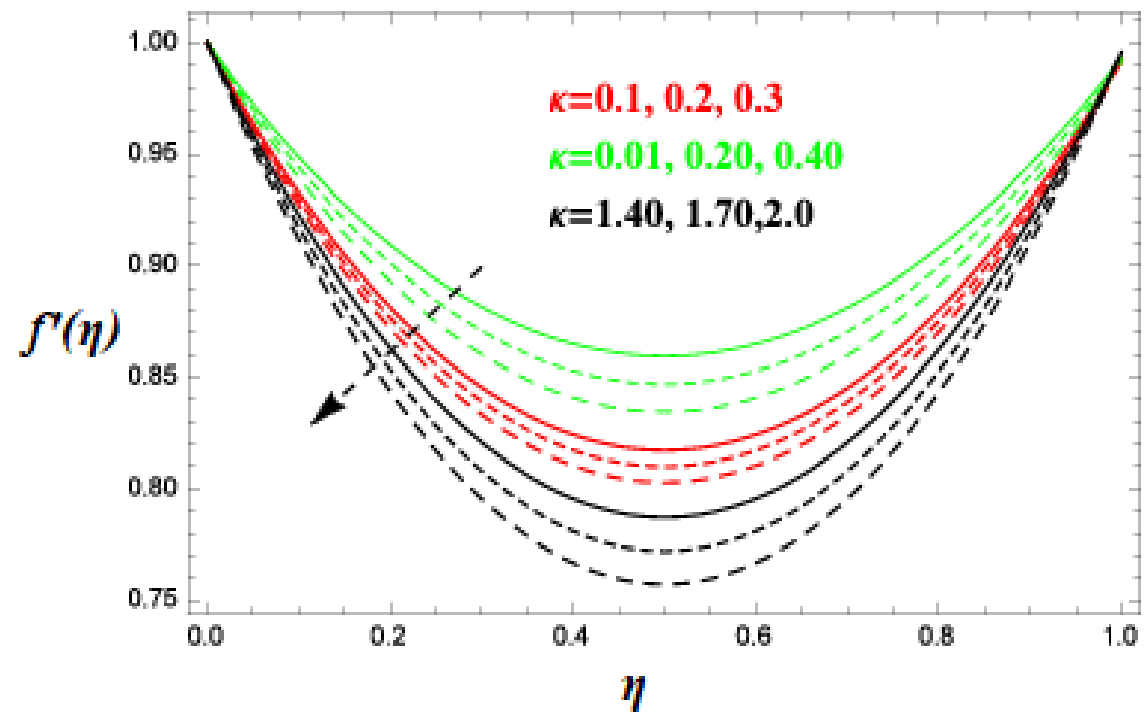

Figure 3. Variations in velocity field $f(\eta)$ for different values of $\kappa$.

Figure 4 shows the effect of $\beta$ during the motion of the flow. Increasing $\beta$ decreases the flow velocity, as it is a reducing function of the velocity and thickness of the liquid film. Substantially, the viscid forces rising with higher numbers of $\beta$ cause the fluid motion. Thus, fluid velocity drops. 


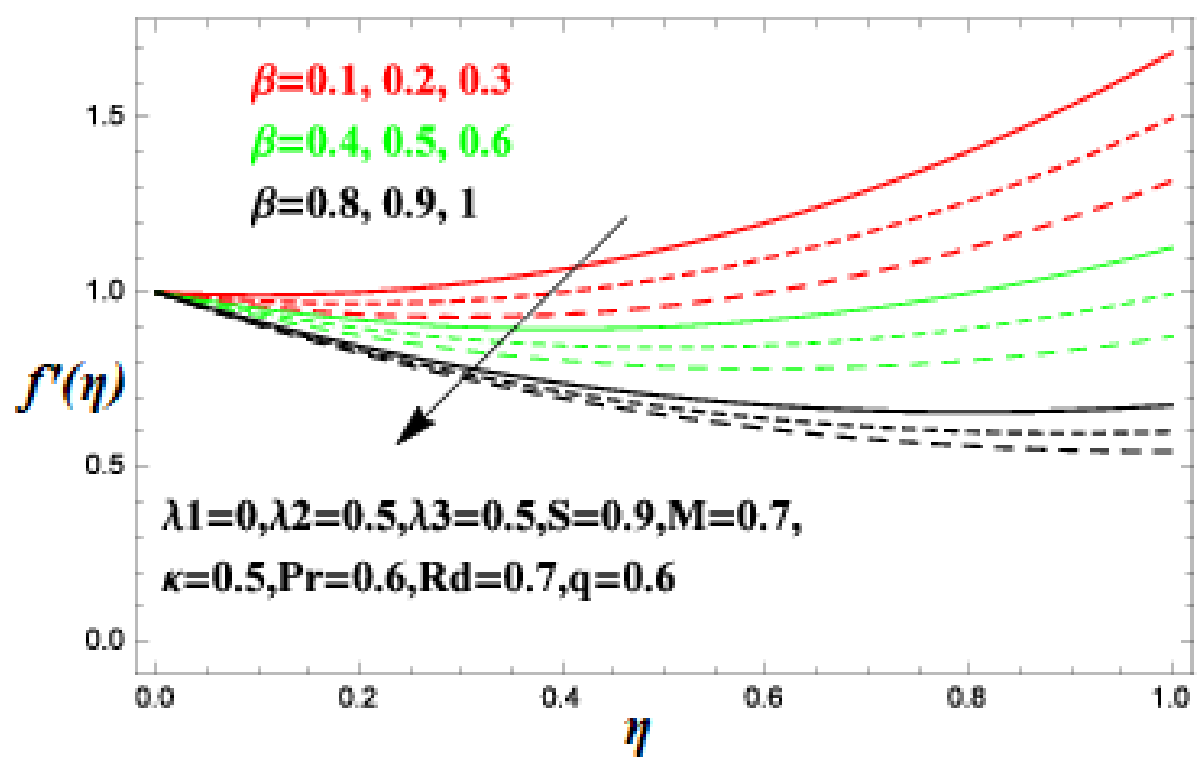

Figure 4. Fluctuations in velocity field $f(\eta)$ for various values of $\beta$.

Figure 5 shows the impact of thin film thickness on the temperature profile. It is observed that an increase in $\beta$ decreases temperature profile $\theta(\eta)$.

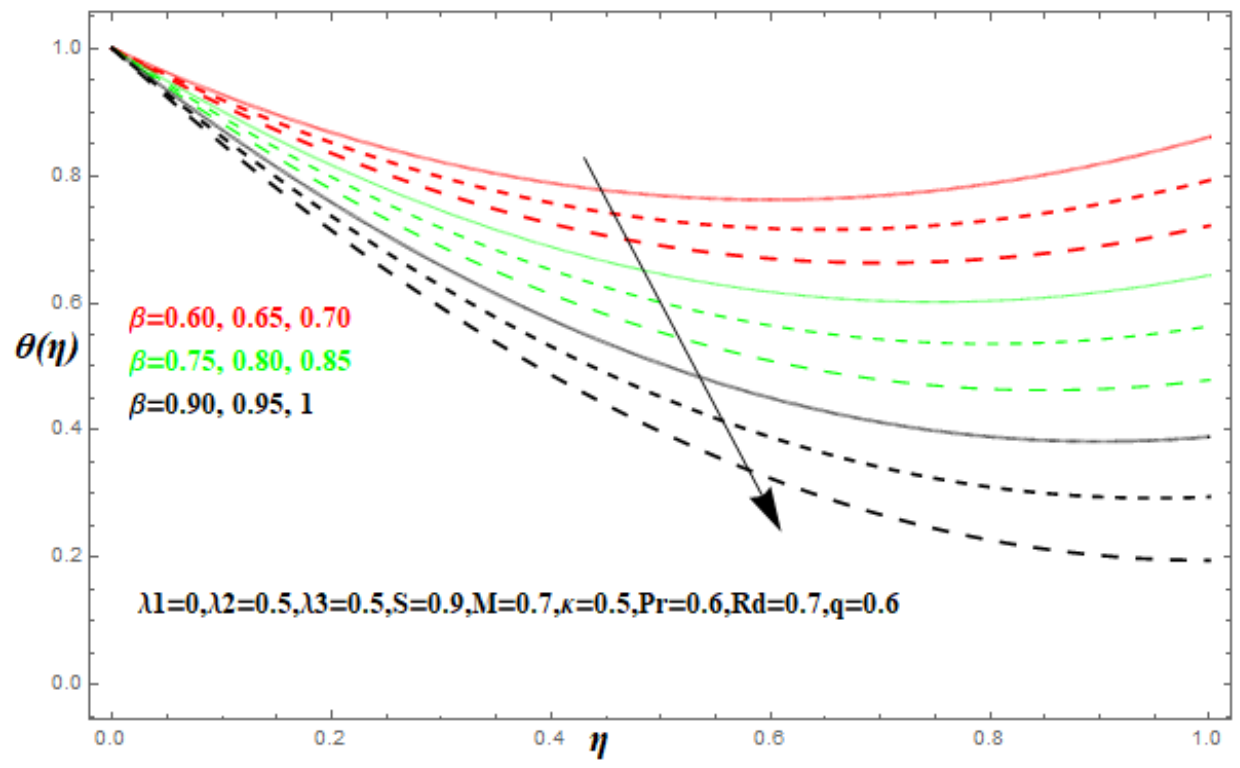

Figure 5. Variations in the temperature gradient $\theta(\eta)$ for the various measures of $\beta$.

Figure 6 describes the features of $M$ on $(\eta)$. The velocity profile reduces due to the rise in $M$. The object of this phenomenon is Lorentz force. This force is responsible for the reduction in the motion of fluid. 


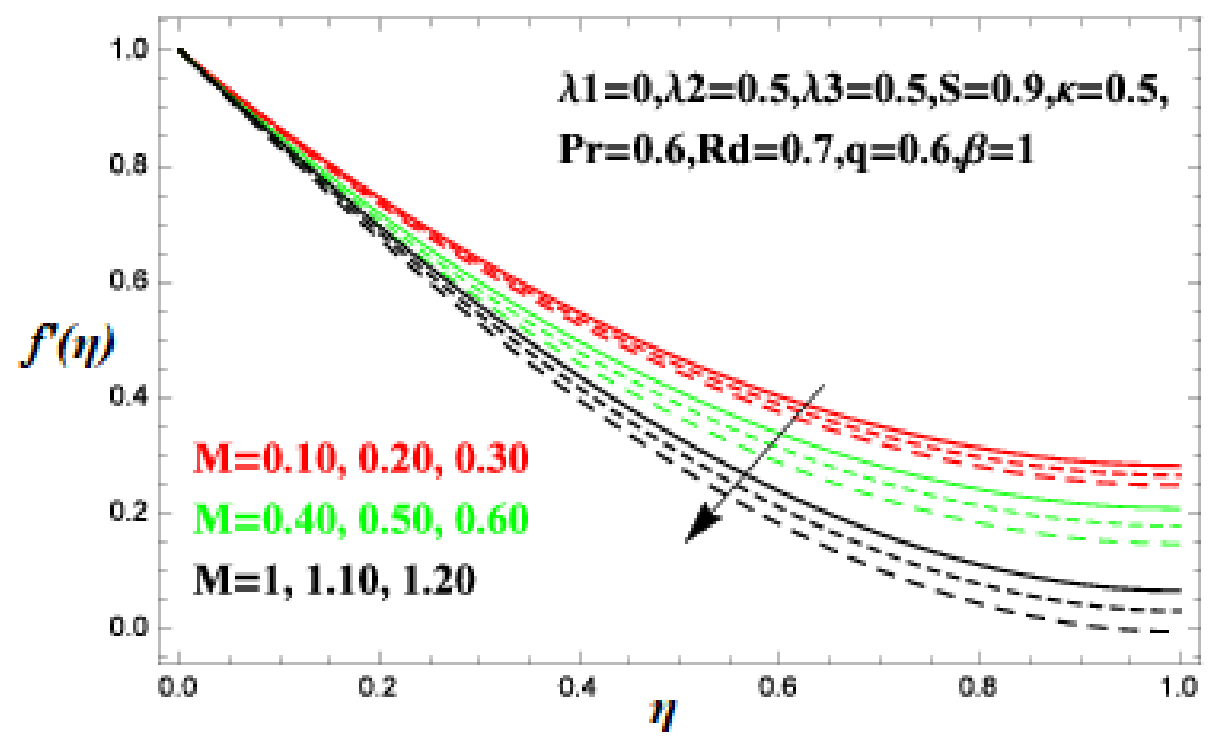

Figure 6. Dissimilarities in $f(\eta)$ for different numbers of $M$.

Figure 7 shows that with different values of $M$, the concentration field increases because an increase in oblique magnetic pitch on the fluid augments the Lorentz force. Lorentz force is the combination of electric and magnetic force on a point charge due to electromagnetic fields. This force is lower at the center of the channel and at the boundaries, but up near the walls. Velocity increases with the unsteady constraint $S$.

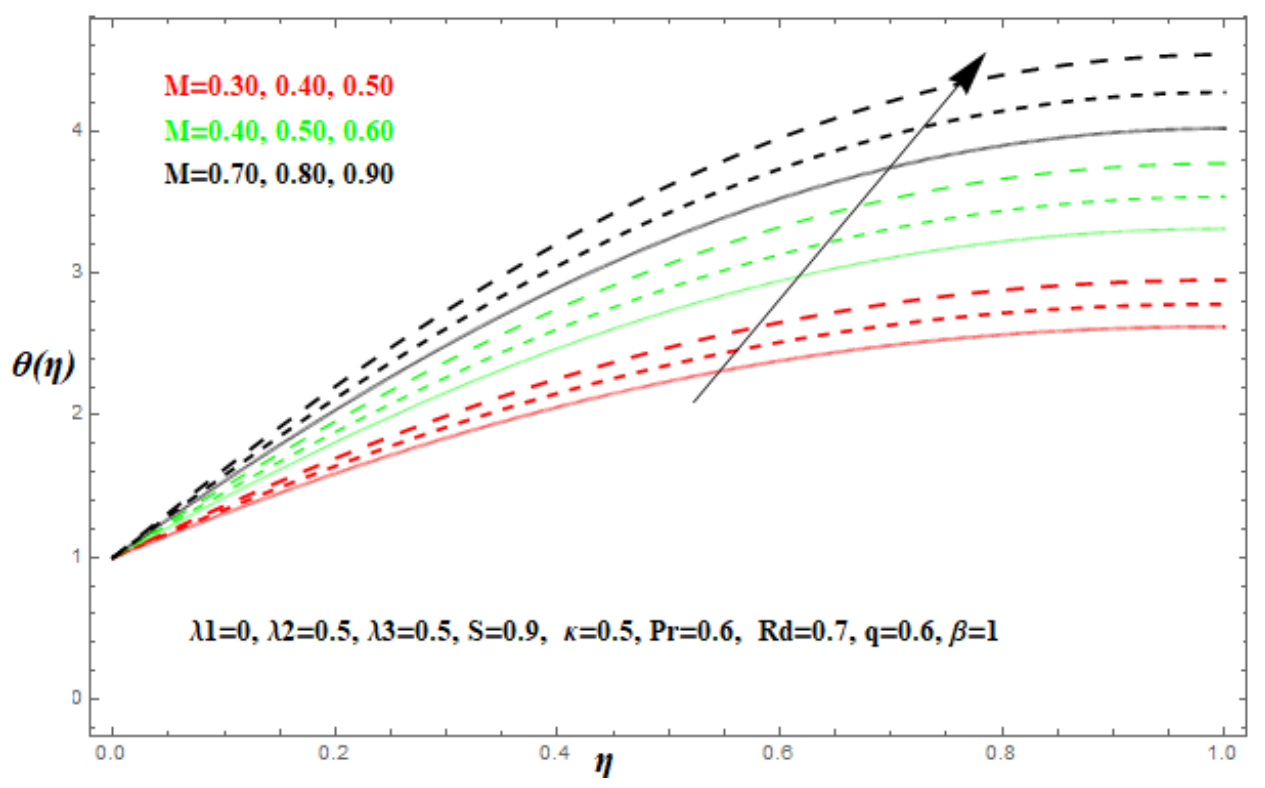

Figure 7. Changes in temperature gradient $\theta(\eta)$ for diverse measures of $M$.

Figure 8 demonstrates the performance of the unsteadiness constraint $S$ on $f(\eta)$. It is concluded that $f(\eta)$ is directly proportional to $S$. The fluid motion increases due to an increase in $S$. Thus, the solution is dependent on $S, S$. 


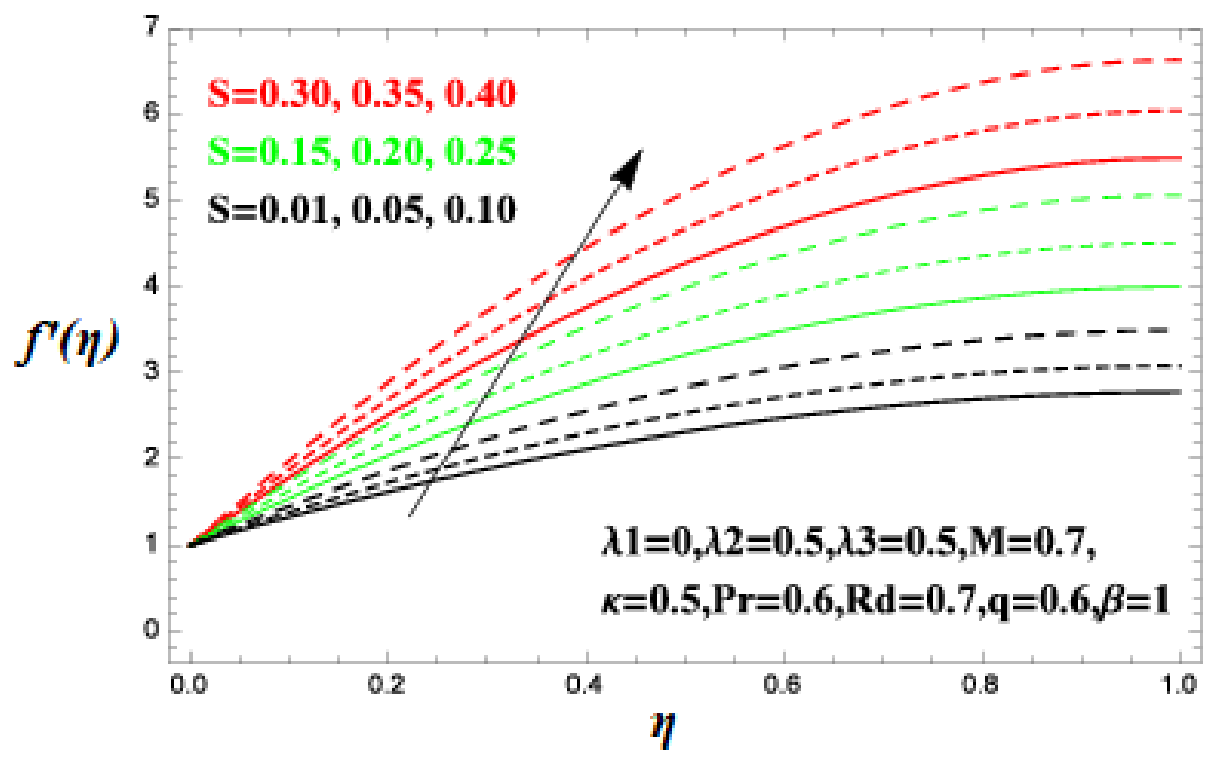

Figure 8. Fluctuations in $f(\eta)$ for several numbers of $S$.

Figure 9 shows the effect of $S$ on the heat profile $\theta(\eta)$. It was concluded that $\theta(\eta)$ is directly proportional to $S$. An increase in the unsteadiness parameter $S$ increases the temperature which, in turn, augments the kinetic energy of the fluid flow; thus, the thin film moment increases.

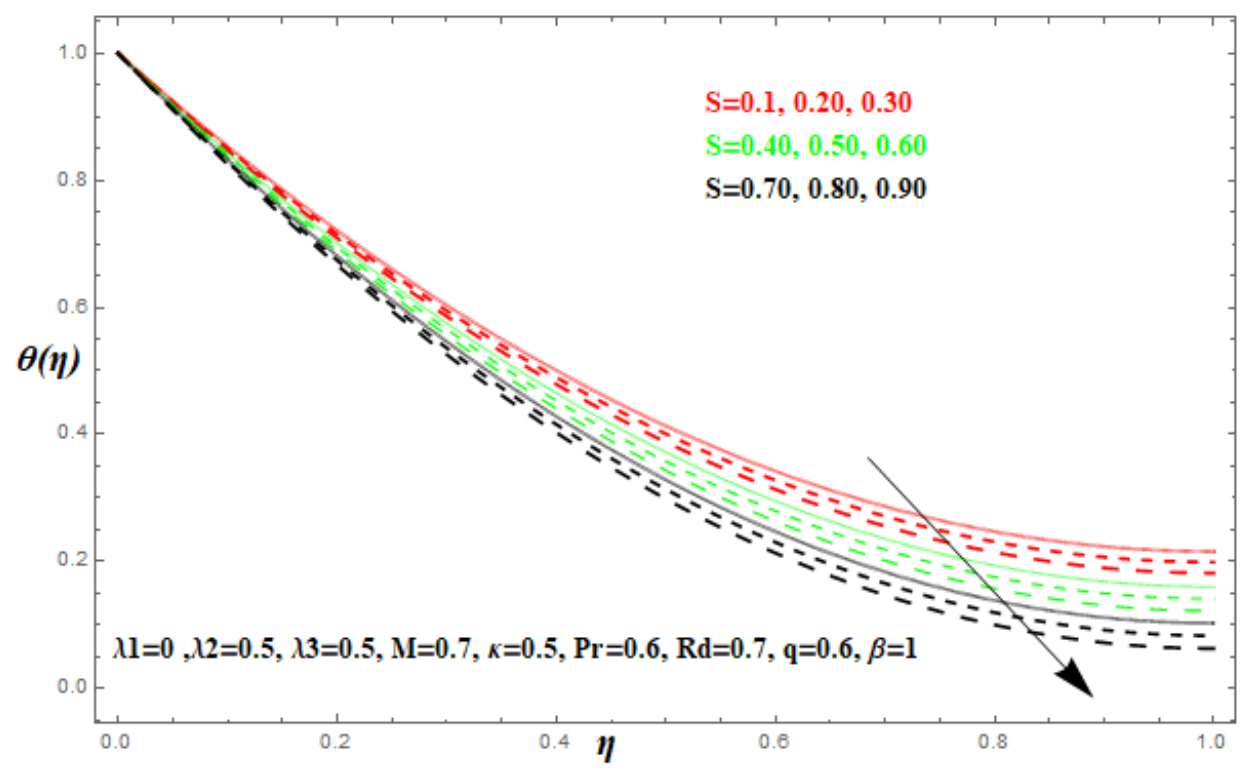

Figure 9. Changes in temperature gradient $\theta(\eta)$ for diverse measures of $S$.

Figure 10 shows the effect of $\mathrm{q}$. Increasing q increases the temperature field. Actually, raising $\mathrm{q}$ increases the kinetic energy of thin film, which results in increasing the internal heat. 


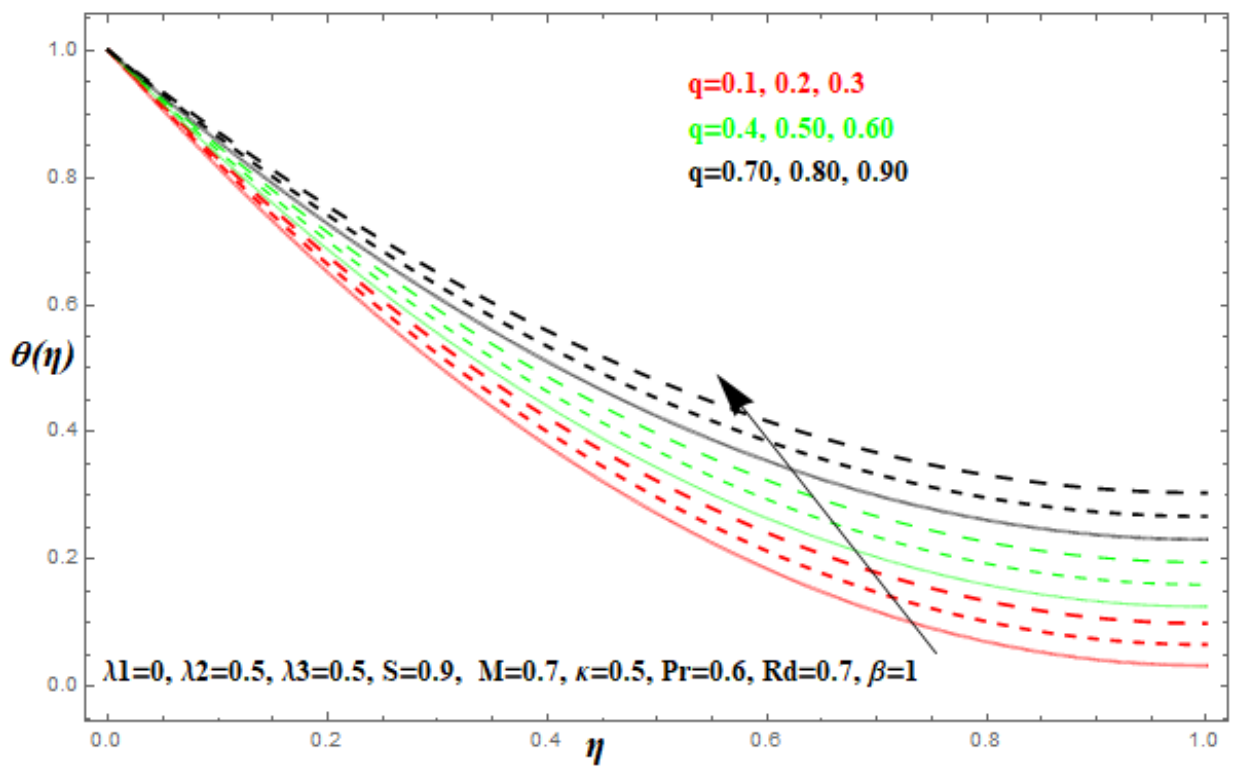

Figure 10. Changes in temperature gradient $\theta(\eta)$ for diverse measures of $q$.

The influence of radioactivity parameter $R d$ on $\theta(\eta)$ is shown in Figure 11. Radioactivity is an important part on the inclusive surface heat transmission when the coefficient of convection heat transmission is small. When thermal radiation is increased, the thermal radiation augments the temperature in the boundary layer area in the fluid layer. This increase leads to a drop in the rate of cooling for liquid film flow.

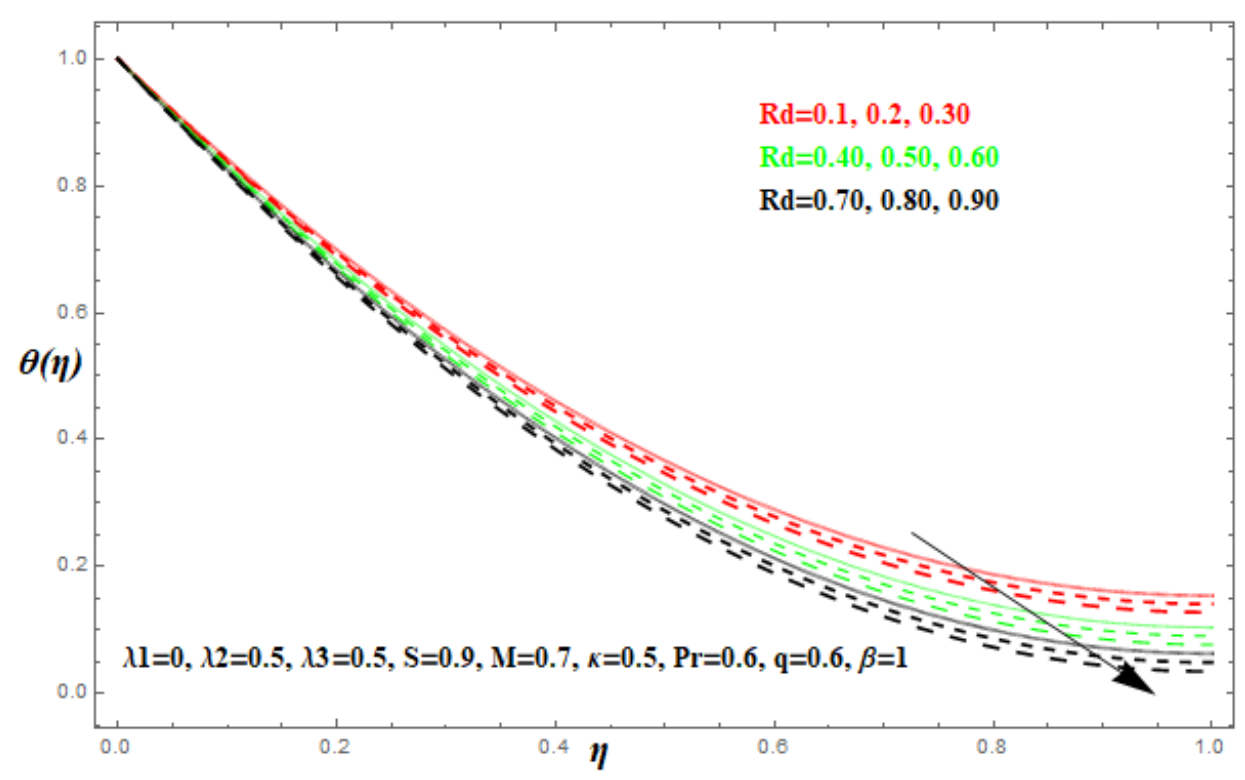

Figure 11. Changes in temperature gradient $\theta(\eta)$ for diverse measures of $R d$.

The influence of $\operatorname{Pr}$ on the temperature distributions $\theta(\eta)$ is shown in Figure 12. The temperature distribution varies inversely with $P r$. Clearly, the temperature distribution decreases for large values of $P r$ and increases for small values of $P r$. Physically, the fluids having a small $P r$ have larger thermal diffusivity and vice versa. Thus, large $\operatorname{Pr}$ causes the thermal boundary layer to decrease. 


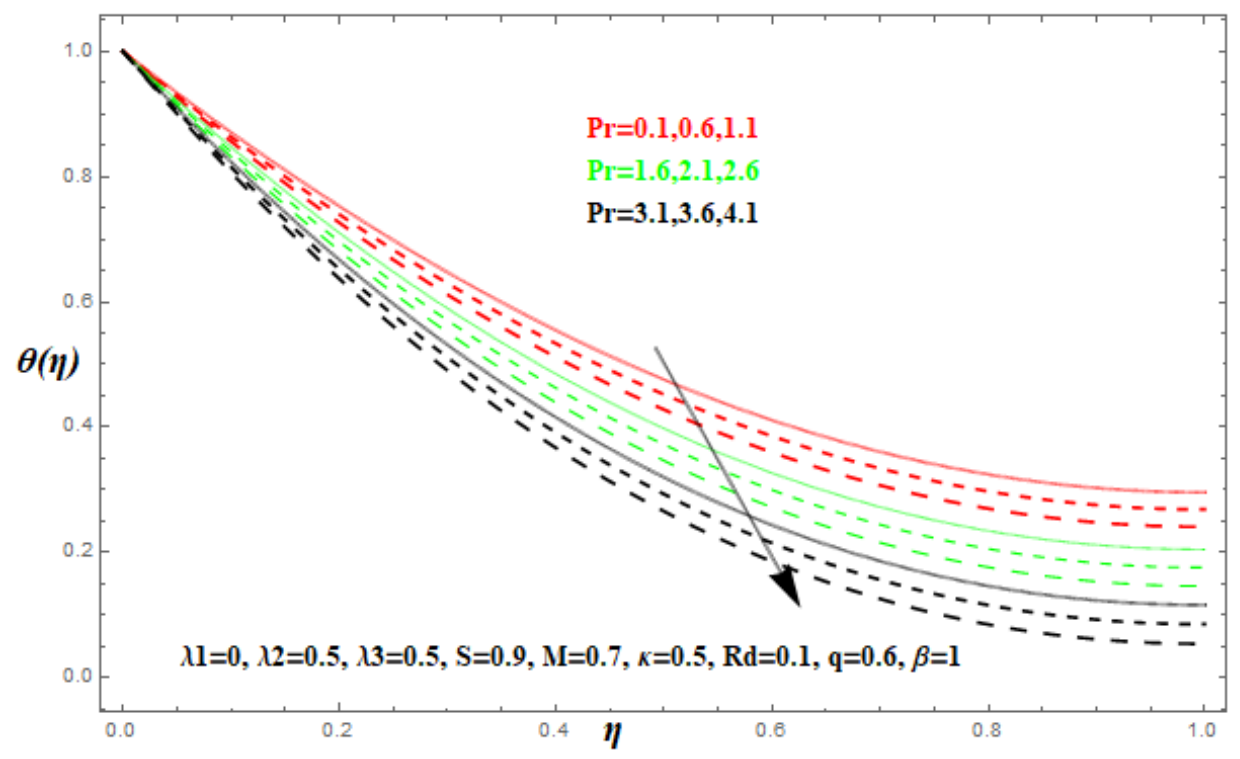

Figure 12. Changes in temperature gradient $\theta(\eta)$ for diverse measures of $\operatorname{Pr}$.

Figures 13 and 14 illustrate the comparison of HAM and numerical solution for velocities and temperature functions. An excellent agreement is found here.

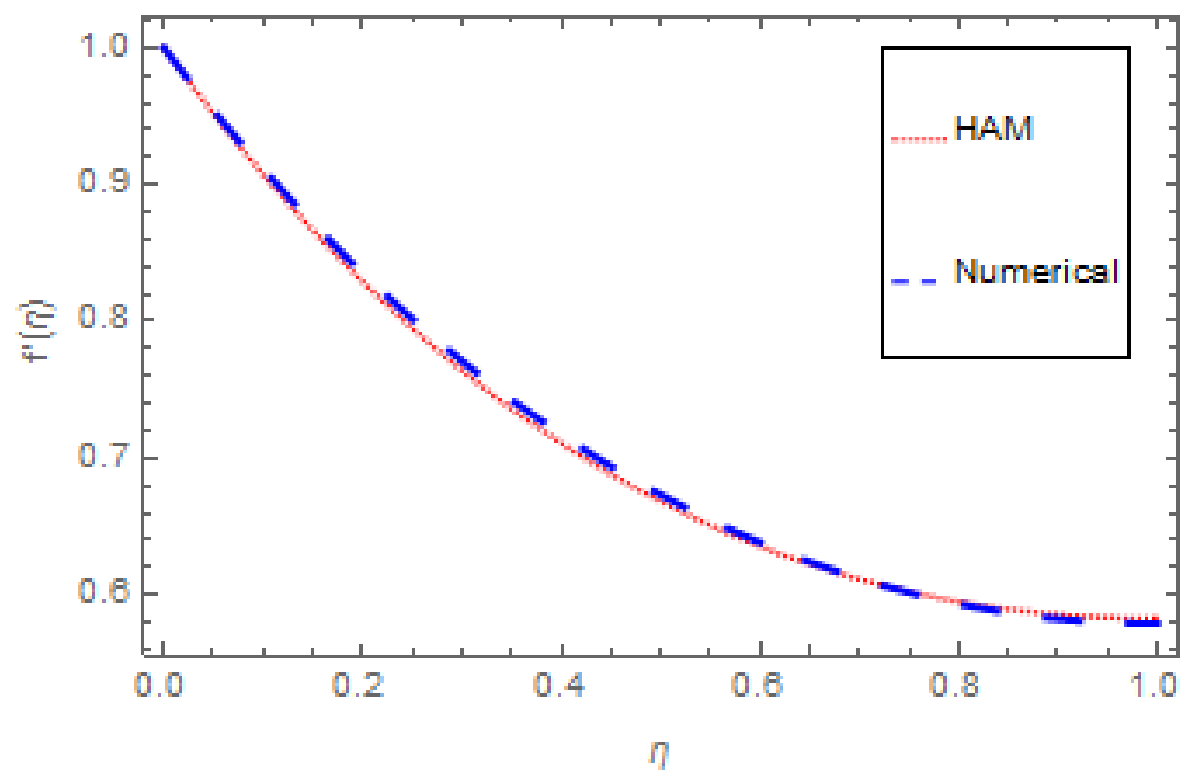

Figure 13. Comparison graph of HAM and numerical solution for $f(\eta)$. 


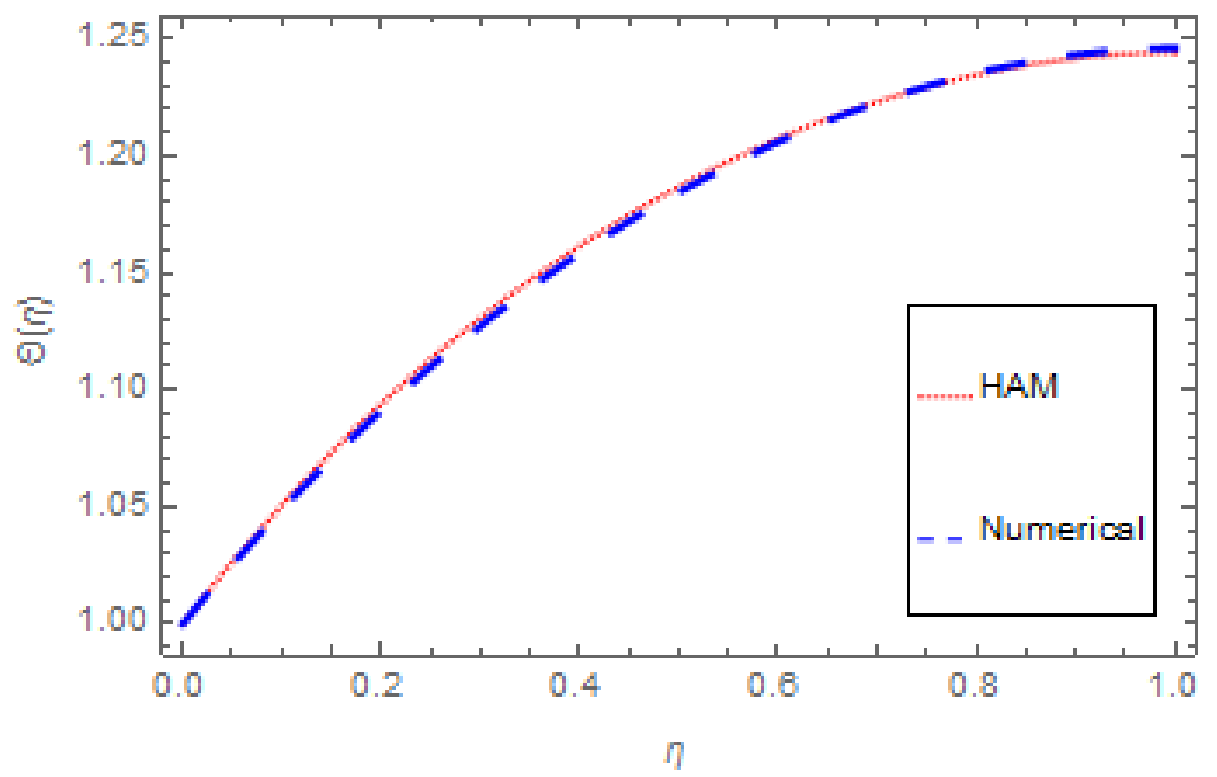

Figure 14. Comparison graph of HAM and numerical solution for $\theta(\eta)$.

Tables 2 and 3 present a comparison of HAM and numerical solution for velocities and temperature functions. We have observed an excellent covenant between the analytical and numerical approach.

The numerical values of surface temperature $\theta(\beta)$ for different values of $M, R d$ and $k$ are given in Table 2. Increasing values of $M, R d$, and $k$ increase surface temperature $\theta(\beta)$, whereas the opposite effect was found for $P r$, that is, large values of $P r$ reduce surface temperature $\theta(\beta)$.

Table 2. Comparison of HAM and numerical solution for $f(\eta)$.

\begin{tabular}{cccc}
\hline $\boldsymbol{\eta}$ & $\begin{array}{c}\text { HAM Solution } \\
\boldsymbol{f}(\boldsymbol{\eta})\end{array}$ & $\begin{array}{c}\text { Numerical Solution } \\
f(\boldsymbol{\eta})\end{array}$ & Absolute Error \\
\hline $\mathbf{0 . 0}$ & 1.00000 & 1.00000 & 0.00000 \\
\hline $\mathbf{0 . 1}$ & 0.907327 & 0.911301 & $3.9 \times 10^{-3}$ \\
\hline $\mathbf{0 . 2}$ & 0.829165 & 0.835332 & $6.2 \times 10^{-3}$ \\
\hline $\mathbf{0 . 3}$ & 0.764141 & 0.770975 & $6.8 \times 10^{-3}$ \\
\hline $\mathbf{0 . 4}$ & 0.710984 & 0.717248 & $6.3 \times 10^{-3}$ \\
\hline $\mathbf{0 . 5}$ & 0.668524 & 0.673301 & $4.8 \times 10^{-3}$ \\
\hline $\mathbf{0 . 6}$ & 0.635691 & 0.638412 & $2.7 \times 10^{-3}$ \\
\hline $\mathbf{0 . 7}$ & 0.611519 & 0.611979 & $4.5 \times 10^{-4}$ \\
\hline $\mathbf{0 . 8}$ & 0.595141 & 0.593511 & $1.8 \times 10^{-3}$ \\
\hline $\mathbf{0 . 9}$ & 0.585791 & 0.582627 & $7.7 \times 10^{-3}$ \\
\hline $\mathbf{1 . 0}$ & 0.582805 & 0.579045 & $3.8 \times 10^{-3}$ \\
\hline
\end{tabular}


Table 3. Comparison of HAM and numerical solution for $\theta(\eta)$.

\begin{tabular}{cccc}
\hline $\boldsymbol{\eta}$ & $\begin{array}{c}\text { HAM Solution } \\
\boldsymbol{\theta}(\boldsymbol{\eta})\end{array}$ & $\begin{array}{c}\text { Numerical Solution } \\
\boldsymbol{\theta}(\boldsymbol{\eta})\end{array}$ & Absolute Error \\
\hline $\mathbf{0 . 0}$ & 1.0000 & 1.00000 & 0.00000 \\
\hline $\mathbf{0 . 1}$ & 1.05078 & 1.04882 & $1.9 \times 10^{-3}$ \\
\hline $\mathbf{0 . 2}$ & 1.09412 & 1.09106 & $3.1 \times 10^{-3}$ \\
\hline $\mathbf{0 . 3}$ & 1.13081 & 1.12742 & $3.3 \times 10^{-3}$ \\
\hline $\mathbf{0 . 4}$ & 1.16156 & 1.15845 & $3.1 \times 10^{-3}$ \\
\hline $\mathbf{0 . 5}$ & 1.18696 & 1.18458 & $2.3 \times 10^{-3}$ \\
\hline $\mathbf{0 . 6}$ & 1.20745 & 1.20608 & $1.3 \times 10^{-3}$ \\
\hline $\mathbf{0 . 7}$ & 1.22335 & 1.22308 & $2.7 \times 10^{-4}$ \\
\hline $\mathbf{0 . 8}$ & 1.23481 & 1.23555 & $7.3 \times 10^{-3}$ \\
\hline $\mathbf{0 . 9}$ & 1.24184 & 1.24331 & $1.4 \times 10^{-3}$ \\
\hline $\mathbf{1 . 0}$ & 1.24425 & 1.2460 & $1.7 \times 10^{-3}$ \\
\hline
\end{tabular}

The numerical value of the gradient of wall temperature $\theta^{\prime}(0)$ for different values of embedded parameters $R d, \beta, P r, S$ is shown in Tables 4 and 5. Larger values of thermal radiation $R d, \beta$, and $\operatorname{Pr}$ decrease the wall temperature, whereas $S$ increases the wall temperature gradient $\theta^{\prime}(0)$.

Table 4. Numerical values for the skin friction coefficient for several physical parameters when: $\lambda_{1}=0.1, \lambda_{2}=1.0, \lambda_{3}=0.1, S=0.5, M=0.6, \kappa=0.7, \operatorname{Pr}=1.0, \beta=1$.

\begin{tabular}{|c|c|c|c|c|c|c|}
\hline$S$ & $\kappa$ & $M$ & $\beta$ & $\begin{array}{c}\frac{1+\lambda_{1}}{1+\lambda_{2}} f^{\prime \prime}(0) \\
\text { Jeffrey Fluid }\end{array}$ & $\begin{array}{c}\frac{1+\lambda_{1}}{1+\lambda_{2}} f^{\prime \prime}(0) \\
\text { Maxwell Fluid }\end{array}$ & $\begin{array}{c}\frac{1+\lambda_{1}}{1+\lambda_{2}} f^{\prime \prime}(0) \\
\text { Oldroyed-B Fluid }\end{array}$ \\
\hline 0.5 & 0.5 & 0.6 & 1.0 & -0.705657 & -1.40417 & -1.29373 \\
\hline 0.6 & & & & -0.690279 & -1.34383 & -1.25575 \\
\hline 0.7 & & & & -0.676699 & -2.19921 & -1.23210 \\
\hline \multirow[t]{10}{*}{0.5} & 0.5 & & & -0.705657 & -1.40417 & -1.29373 \\
\hline & 0.6 & & & -0.719191 & -1.43646 & -1.32213 \\
\hline & 0.7 & & & -0.732514 & -1.46831 & -1.35012 \\
\hline & 0.5 & 0.6 & & -0.705657 & -1.40417 & -1.29373 \\
\hline & & 0.7 & & -0.725666 & -1.44510 & -1.33013 \\
\hline & & 0.8 & & -0.745259 & -1.48521 & -1.36548 \\
\hline & & 0.6 & 1.0 & -0.705657 & -1.40417 & -1.29373 \\
\hline & & & 1.1 & -0.725279 & -1.469866 & -1.33341 \\
\hline & & & 1.2 & -0.740967 & -1.54394 & -0.268147 \\
\hline & & & 1.0 & -0.705657 & -1.40417 & -1.29373 \\
\hline
\end{tabular}


Table 5. Numerical values of the local Nusselt number for several physical parameters, when: $\lambda_{1}=0.1, \lambda_{2}=1.0, \lambda_{3}=0.1, S=0.5, M=0.6, \kappa=0.7, \operatorname{Pr}=1.0, \beta=1, R d=0.5, q=0.5$.

\begin{tabular}{|c|c|c|c|c|c|c|c|c|}
\hline$S$ & $\kappa$ & $M$ & $\beta$ & $R d$ & $q$ & $\begin{array}{c}\theta^{\prime}(0) \\
\text { Jeffrey Fluid }\end{array}$ & $\begin{array}{c}\theta^{\prime}(0) \\
\text { Maxwell Fluid }\end{array}$ & $\begin{array}{c}\theta^{\prime}(0) \\
\text { Oldroyed-B Fluid }\end{array}$ \\
\hline 0.5 & 0.5 & 0.6 & 1.0 & 0.5 & 0.5 & -0.550388 & -0.590996 & -0.616292 \\
\hline 0.6 & & & & & & -0.545322 & -0.590885 & -0.611008 \\
\hline 0.7 & & & & & & -0.539440 & -0.683523 & -0.605811 \\
\hline \multirow[t]{13}{*}{0.5} & 0.5 & & & & & -0.550388 & -0.590996 & -0.616292 \\
\hline & 0.6 & & & & & -0.543228 & -0.582409 & -0.608402 \\
\hline & 0.7 & & & & & -0.536265 & -0.574031 & -0.600680 \\
\hline & 0.5 & 0.6 & & & & -0.550388 & -0.590996 & -0.616292 \\
\hline & & 0.7 & & & & -0.538941 & -0.580121 & -0.605984 \\
\hline & & 0.8 & & & & -0.527911 & -0.569593 & -0.595950 \\
\hline & & 0.6 & 1.0 & & & -0.550388 & -0.590996 & -0.616292 \\
\hline & & & 1.1 & & & -0.551698 & -0.589585 & -0.619001 \\
\hline & & & 1.2 & & & -0.547039 & -0.580929 & -0.376664 \\
\hline & & & 1.0 & 0.5 & & -0.550388 & -0.590996 & -0.616292 \\
\hline & & & & 0.6 & & -0.517715 & -0.555700 & -0.579345 \\
\hline & & & & 0.7 & & -0.488677 & -0.524350 & -0.546542 \\
\hline & & & & 0.5 & 0.5 & -0.550388 & -0.590996 & -0.616292 \\
\hline
\end{tabular}

\section{Conclusions}

The MHD flow of three combined fluids, Maxwell, Jeffry, and Oldroyed-B fluid, with variable heat transmission under the influence of thermal radiation was investigated. The fundamental leading equations were changed to a set of differential nonlinear and coupled equations. An optimal and numerical tactic was used to acquire the solution of the modeled problems.

The key conclusions of this work are as follows:

- The velocity profile shows an increase with increasing values of the unsteadiness parameter $S t$, while increasing values of the magnetic parameter cause the decline of the velocity profile of the nanofluid film.

- Rd augmented heat flux

- Higher values of Pr increase the surface temperature.

- Fast convergence is shown numerically and graphically.

- The liquid film flow effects on the flow of three fluids (Jeffrey, Maxwell, and Oldroyd-B fluids) are presented using graphs and tables.

- It was found that the coefficient of skin friction rises with the larger rates of the magnetic parameter $M$ and the unsteadiness parameter $S t$, whereas the coefficient of skin friction decreases with the higher values of the stretching and thickness parameters.

- It was found that liquid film flow is affected by the Lorentz's force.

- The obtained analytical and numerical consequences are presented graphically and tabulated. An excellent agreement was obtained between HAM and the numerical method.

Author Contributions: A.S.K. and Z.S. modeled the problem and wrote the manuscript. Y.N. thoroughly checked the mathematical modeling and English corrections. A.S.K. and Z.S. solved the problem using Mathematica software. Y.N. contributed to the results and discussions. All authors finalized the manuscript after its internal evaluation. 
Funding: This research was funded by National Natural Science Foundation of China No. [11471262].

Conflicts of Interest: The authors declare no conflict of interest.

\section{Nomenclature}

$J$ Current density $\mu$ Coefficient of viscosity $T$ Cauchy stress tensor $\sigma$ Electric conductivity E Electric field $\omega$ Frequency parameter $p$ pressure I Identity tensor chord St Unsteadiness parameter Pr Prandtl number $C_{f}$ Skin friction

\author{
$\alpha_{1}, \alpha_{2}$ Material constants \\ $\mu_{0}$ Magnetic permeability \\ $M$ Magnetic parameter \\ $\alpha$ non-Newtonian parameter \\ $\Omega$ Pressure gradient parameter \\ $A_{1}$ and $A_{2}$ Rivlin-Ericksen tensor \\ $t$ Time variable \\ $R d$ Radiation paramete
}

$\mathrm{Nu}$ Nusselt number

\section{References}

1. Emslie, A.G.; Bonner, F.T.; Peck, L.G. Flow of a viscous liquid on a rotating disk. J. Appl. Phys. 1958, 5, 858-862. [CrossRef]

2. Higgins, B.G. Film flow on a rotating disk. Phy. Fluids. 1986, 29. [CrossRef]

3. Dorfman, I.A. Flow and heat transfer in a film of viscous liquid on a rotating disk. J. Eng. Phys. 1967, 12, 162-166. [CrossRef]

4. Wang, C.Y.; Watson, L.T.; Alexander, K.A. Spinning of a liquid.lm from an accelerating disc. IMA J. Appl. Math. 1991, 46, 201-210. [CrossRef]

5. Andersson, H.I.; Holmedal, B.; Dandapat, B.S.; Gupta, A.S. Magnetohydrodynamic melting flow from a horizontal rotating disk. Math. Models Methods Appl. Sci. 1993, 3. [CrossRef]

6. Dandapat, B.S.; Singh, S.K. Unsteady two-layer film flow on a non-uniform rotating disk in presence of uniform transverse magnetic field. Appl. Math. Comput. 2015, 258, 545-555. [CrossRef]

7. Sandeep, N.; Malvandi, A. Enhanced heat transfer in liquid thin film flow of non-Newtonian nanofluids embedded with graphene nanoparticles. Adv. Powder Technolog. 2016, 27, 2448-2456. [CrossRef]

8. Khan, N.; Zuhra, S.; Shah, Z.; Bonyah, E.; Khan, W.; Islam, S. Slip flow of Eyring-Powell nanoliquid film containing graphene nanoparticles. AIP Adv. 2018, 8. [CrossRef]

9. Ullah, A.; Alzahrani, E.O.; Shah, Z.; Ayaz, M.; Islam, S. Nanofluids Thin Film Flow of Reiner-Philippoff Fluid over an Unstable Stretching Surface with Brownian Motion and Thermophoresis Effects. Coatings 2019, 9, 21. [CrossRef]

10. Shah, Z.; Bonyah, E.; Islam, S.; Khan, W.; Ishaq, M. Radiative MHD thin film flow of Williamson fluid over an unsteady permeable stretching. Heliyon 2018, 4. [CrossRef]

11. Ishaq, M.; Ali, G.; Shah, S.I.A.; Shah, Z.; Muhammad, S.; Hussain, S.A. Nanofluid Film Flow of Eyring Powell Fluid with Magneto Hydrodynamic Effect on Unsteady Porous Stretching Sheet. J. Math. 2019, 51, 131-153.

12. Jawad, M.; Shah, Z.; Islam, S.; Islam, S.; Bonyah, E.; Khan, Z.A. Darcy-Forchheimer flow of MHD nanofluid thin film flow with Joule dissipation and Navier's partial slip. J. Phys. Commun. 2018, 2. [CrossRef]

13. Jawad, M.; Shah, Z.; Islam, S.; Majdoubi, J.; Tlili, I.; Khan, W.; Khan, I. Impact of Nonlinear Thermal Radiation and the Viscous Dissipation Effect on the Unsteady Three-Dimensional Rotating Flow of Single-Wall Carbon Nanotubes with Aqueous Suspensions. Symmetry 2019, 11, 207. [CrossRef]

14. Khan, N.S.; Gul, T.; Islam, S.; Khan, A.; Shah, Z. Brownian Motion and Thermophoresis Effects on MHD Mixed Convective Thin Film Second-Grade Nanofluid Flow with Hall Effect and Heat Transfer Past a Stretching Sheet. J. Nanofluids 2017, 6, 1-18. [CrossRef]

15. Tahir, F.; Gul, T.; Islam, S.; Shah, Z.; Khan, A.; Khan, W.; Ali, L.; Muradullah. Flow of a Nano-Liquid Film of Maxwell Fluid with Thermal Radiation and Magneto Hydrodynamic Properties on an Unstable Stretching Sheet. J. Nanofluids 2017, 6, 1-10. [CrossRef]

16. Kartini, A.; Zahir, H.; Anuar, I. Mixed convection Jeffrey fluid flow over an exponentially stretching sheet with magnetohydrodynamic effect. AIP Adv. 2016, 6. [CrossRef] 
17. Hayat, T.; Hussain, T.; Shehzad, S.A.; Alsaedi, A. Flow of Oldroyd-B fluid with nano particles and thermal radiation. Appl. Math. Mech. Engl. Ed. 2015, 36, 69-80. [CrossRef]

18. Raju, C.S.K.; Sandeep, N.; Gnaneswar, R.M. Effect of nonlinear thermal radiation on 3D Jeffrey fluid flow in the presence of homogeneous-heterogeneous reactions. Int. J. Eng. Res. Afr. 2016, 21, 52-68. [CrossRef]

19. Hayat, T.; Abbas, Z.; Sajid, M. Series solution for the upper convected Maxwell fluid over a porous stretching plate. Phys. Lett. A 2006, 358, 396-403. [CrossRef]

20. Sandeep, N.; Sulochana, C. Dual solutions for unsteady mixed convection flow of MHD micropolar fluid over a stretching/shrinking sheet with non-uniform heat source/sink. Eng. Sci. Technol. Int. J. 2015, 18. [CrossRef]

21. Nadeem, S.; Akbar, N.S. Influence of haet and mass transfer on a peristaltic motion of a Jeffrey-six constant fluid in an annulus. Heat Mass. Transfer. 2010, 46, 485-493. [CrossRef]

22. Sheikholeslami, M.; Shah, Z.; Shafi, A.; Khan, I.; Itili, I. Uniform magnetic force impact on water based nanofluid thermal behavior in a porous enclosure with ellipse shaped obstacle. Sci. Rep. 2019, 9, 1196. [CrossRef] [PubMed]

23. Sheikholeslami, M.; Shah, Z.; Tassaddiq, A.; Shafee, A.; Khan, I. Application of Electric Field for Augmentation of Ferrofluid Heat Transfer in an Enclosure Including Double Moving Walls. IEEE Access 2019, 7, 21048-21056. [CrossRef]

24. Shah, Z.; Dawar, A.; Islam, S.; Khan, I.; Ching, D.L.C. Darcy-Forchheimer Flow of Radiative Carbon Nanotubes with Microstructure and Inertial Characteristics in the Rotating Frame. Case Stud. Thermal Eng. 2018, 12, 823-832. [CrossRef]

25. Shah, Z.; Islam, S.; Ayaz, H.; Khan, S. Radiative Heat and Mass Transfer Analysis of Micropolar Nanofluid Flow of Casson Fluid between Two Rotating Parallel Plates with Effects of Hall Current. ASME J. Heat Transf. 2019, 141. [CrossRef]

26. Shah, Z.; Islam, S.; Gul, T.; Bonyah, E.; Altaf Khan, M. The Elcerical MHD And Hall Current Impact On Micropolar Nanofluid Flow Between Rotating Parallel Plates. Res. Phys. 2018, 9. [CrossRef]

27. Shah, Z.; Bonyah, E.; Islam, S.; Gul, T. Impact of thermal radiation on electrical mhd rotating flow of carbon nanotubes over a stretching sheet. AIP Adv. 2019, 9. [CrossRef]

28. Shah, Z.; Dawar, A.; Islam, S.; Khan, I.; Ching, D.L.C.; Khan, A.Z. Cattaneo-Christov model for Electrical MagnetiteMicropoler Casson Ferrofluid over a stretching/shrinking sheet using effective thermal conductivity model. Case Stud. Therm. Eng. 2018, 13, 100352. [CrossRef]

29. Shah, Z.; Tassaddiq, A.; Islam, S.; Alklaibi, A.; Khan, I. Cattaneo-Christov Heat Flux Model for Three-Dimensional Rotating Flow of SWCNT and MWCNT Nanofluid with Darcy-Forchheimer Porous Medium Induced by a Linearly Stretchable Surface. Symmetry 2019, 11, 331. [CrossRef]

30. Dawar, A.; Shah, Z.; Islam, S.; Idress, M.; Khan, W. Magnetohydrodynamic CNTs Casson Nanofl uid and Radiative heat transfer in a Rotating Channels. J. Phys. Res. Appl. 2018, 1, 17-32.

31. Khan, A.S.; Nie, Y.; Shah, Z.; Dawar, A.; Khan, W.; Islam, S. Three-Dimensional Nanofluid Flow with Heat and Mass Transfer Analysis over a Linear Stretching Surface with Convective Boundary Conditions. Appl. Sci. 2018, 8, 2244. [CrossRef]

32. Lee, L.L. Boundary layer over a thin needle. Phys. Fluids. 1967, 10, 822-828. [CrossRef]

33. Usha, S.; Ramachandra, R.R. Peristaltic transport of two-layered power-law fluids. J. Biomech. Eng. 1997, 119, 483-488. [CrossRef]

34. Eegunjobi, A.S.; Makinde, O.D. Combined effect of buoyancy force and Navier slip on entropy generation in a vertical porous channel. Entropy 2012, 14, 1028-1044. [CrossRef]

35. Makinde, O.D.; Chinyoka, T. Numerical investigation of buoyancy effects on hydromagnetic unsteady flow through a porous channel with suction/injection. Mech. Sci. Technol. 2013, 27, 1557-1568. [CrossRef]

36. Liao, S.J. An explicit totally analytic approximate solution for Blasius viscous flow problems. Int. J. Non-Linear Mech. 1999, 34, 759-778. [CrossRef]

37. Liao, S.J. On the analytic solution of Magneto hydrodynamic flows of non-Newtonian fluids over a stretching sheet. J. Fluid Mech. 2003, 488, 189-212. [CrossRef]

38. Nasir, S.; Shah, Z.; Islam, S.; Khan, W.; Khan, S.N. Radiative flow of magneto hydrodynamics single-walled carbon nanotube over a convectively heated stretchable rotating disk with velocity slip effect. Adv. Mech. Eng. 2019, 11, 1-11. [CrossRef] 
39. Nasir, S.S.; Shah, Z.; Islam, S.; Khan, W.; Bonyah, E.; Ayaz, M.; Khan, A. Three dimensional Darcy-Forchheimer radiated flow of single and multiwall carbon nanotubes over a rotating stretchable disk with convective heat generation and absorption. AIP Adv. 2019, 9. [CrossRef]

40. Khan, A.; Shah, Z.; Islam, S.; Dawar, A.; Bonyah, E.; Ullah, H.; Khan, Z.A. Darcy-Forchheimer flow of MHD CNTs nanofluid radiative thermal behaviour andconvective non uniform heat source/sink in the rotating frame with microstructureand inertial characteristics. AIP Adv. 2018, 8. [CrossRef]

41. Khan, A.; Shah, Z.; Islam, S.; Khan, S.; Khan, W.; Khan, Z.A. Darcy-Forchheimer flow of micropolar nanofluid between two plates in the rotating frame with non-uniform heat generation/absorption. Adv. Mech. Eng. 2018, 10, 1-16. [CrossRef]

42. Feroz, N.; Shah, Z.; Islam, S.; Alzahrani, E.O.; Khan, W. Entropy Generation of Carbon Nanotubes Flow in a Rotating Channel with Hall and Ion-Slip Effect Using Effective Thermal Conductivity Model. Entropy 2019, 21, 52. [CrossRef]

43. Alharbi, S.O.; Dawar, A.; Shah, Z.; Khan, W.; Idrees, M.; Islam, S.; Khan, I. Entropy Generation in MHD Eyring-Powell Fluid Flow over an Unsteady Oscillatory Porous Stretching Surface under the Impact of Thermal Radiation and Heat Source/Sink. Appl. Sci. 2018, 8, 2588. [CrossRef]

44. Muhammad, S.; Ali, G.; Shah, Z.; Islam, S.; Hussain, S.A. The Rotating Flow of Magneto Hydrodynamic Carbon Nanotubes over a Stretching Sheet with the Impact of Non-Linear Thermal Radiation and Heat Generation/Absorption. Appl. Sci. 2018, 8, 482. [CrossRef]

45. Saeed, A.; Islam, S.; Dawar, A.; Shah, Z.; Kumam, P.; Khan, W. Influence of Cattaneo-Christov Heat Flux on MHD Jeffrey, Maxwell, and Oldroyd-B Nanofluids with Homogeneous-Heterogeneous Reaction. Symmetry 2019, 11, 439. [CrossRef]

46. Shang, Y. Analytical Solution For An In-Host Viral Infection Model With Time-Inhomogeneous Rates. Acta Phys. Polon. B 2015, 46, 1567-1577. [CrossRef]

47. Shang, Y. A lie algebra approach to susceptible-infected-susceptible epidemics. Electr. J. Different. Equat. 2012, 233, 1-7.

48. Shang, Y. Lie algebraic discussion for aflnity based information diffusion in social networks. Open Phys. 2017, 15, 705-711. [CrossRef] 